\title{
Weight status and gender-related differences in motor skills and in child care - based physical activity in young children
}

Antoine Bonvin ${ }^{1 *}$, Jérôme Barral ${ }^{1}$, Tanja H Kakebeeke ${ }^{2}$, Susi Kriemler ${ }^{3}$, Anouk Longchamp ${ }^{4}$, Pedro Marques-Vidal ${ }^{5}$ and Jardena J Puder ${ }^{5}$

\begin{abstract}
Background: Over the last decades, a decline in motor skills and in physical activity and an increase in obesity has been observed in children. However, there is a lack of data in young children. We tested if differences in motor skills and in physical activity according to weight or gender were already present in 2- to 4-year-old children.

Methods: Fifty-eight child care centers in the French part of Switzerland were randomly selected for the Youp'là bouge study. Motor skills were assessed by an obstacle course including 5 motor skills, derived from the Zurich Neuromotor Assessment test. Physical activity was measured with accelerometers (GT1M, Actigraph, Florida, USA) using age-adapted cut-offs. Weight status was assessed using the International Obesity Task Force criteria (healthy weight vs overweight) for body mass index (BMI).

Results: Of the 529 children ( $49 \%$ girls, $3.4 \pm 0.6$ years, BMl $16.2 \pm 1.2 \mathrm{~kg} / \mathrm{m}^{2}$ ), 13\% were overweight. There were no significant weight status-related differences in the single skills of the obstacle course, but there was a trend ( $p$ $=0.059)$ for a lower performance of overweight children in the overall motor skills score. No significant weight status-related differences in child care-based physical activity were observed. No gender-related differences were found in the overall motor skills score, but boys performed better than girls in 2 of the 5 motor skills ( $p \leq 0.04$ ). Total physical activity as well as time spent in moderate-vigorous and in vigorous activity during child care were $12-25 \%$ higher and sedentary activity $5 \%$ lower in boys compared to girls (all $p<0.01$ ).

Conclusions: At this early age, there were no significant weight status- or gender-related differences in global motor skills. However, in accordance to data in older children, child care-based physical activity was higher in boys compared to girls. These results are important to consider when establishing physical activity recommendations or targeting health promotion interventions in young children.
\end{abstract}

Keywords: Children, Motor skills, Physical activity, Gender, Overweight, Youp'là bouge

\section{Background}

The prevalence of overweight and obesity has reached epidemic levels [1], even in young children [2]. Moreover, fitness levels of school children have significantly declined over the three last decades [3], and a decline in some motor skills of preschoolers [4], as well as in physical activity of school children [5] has also been observed. In addition, physical activity and motor skills

\footnotetext{
*Correspondence: antoine.bonvin@unil.ch

'Institute of Sport Sciences, University of Lausanne, Bâtiments administratifs de Vidy, Route de Chavannes 33, 1015 Lausanne, Switzerland

Full list of author information is available at the end of the article
}

in children may underlie a reciprocal and dynamic relationship, which is mediated by factors such as aerobic fitness and obesity [6-8].

Weight status-related differences in motor skills $[9,10]$ and in measured physical activity $[11,12]$ are well documented in school children, though some controversy remains [13]. However, as prevention strategies are proposed to start at preschool age [14-18], it is also important to assess motor skills and physical activity levels in this younger age group in order to avoid large discrepancies. The few existing studies conducted in 4- to 6year-old preschool children report controversial findings 
regarding weight status-related differences in motor skills [19-21] and in objectively measured physical activity $[22,23]$. To our knowledge, no studies investigating differences in motor skills and in physical activity between healthy weight and overweight children below age 4 have been performed.

In preschoolers, weight status-related differences in physical activity have been postulated to be genderdependant with more pronounced differences in boys [23]. In this context, the question arises, if there are also gender differences in physical activity in preschoolers or in even younger children. Although previous studies hint to gender differences in infants ( 0 to 12 months) [24], data using accelerometers, the gold standard of physical activity measurements in a more epidemiological context [25], are lacking in children before entering preschool. In two studies [22,26], accelerometers have been used in 3- to 5-year-old preschoolers. In both studies, gender differences in physical activity were found with boys being more active than girls. However, this observation was not confirmed in another study [27]. Similarly, it remains controversial if gender differences in motor skills already exist in preschoolers [26,27]. Moreover, studies including children below age 4 are rather scarce.

Hence, in this study, we used data from the Youp'là Bouge study to investigate weight status and genderrelated differences in motor skills and physical activity in 2- to 4-year-old children.

\section{Methods}

The "Youp'là bouge" study (clinical trials.gov NCT00967460), is a randomized controlled trial conducted in 58 randomly selected public child care centers in urban and rural areas of the French-speaking part of Switzerland (cantons of Vaud, Neuchâtel and Jura). Thereby, the governmental institution that ran the program randomly selected 20 of the existing child care centers in each of the three cantons. Two centers withdrew before beginning the study. Thus, a total of 58 child care centers participated in the study. The present analysis focuses on the baseline data of this physical activity program. Half of the child care centers were then randomly assigned to the intervention $(n=29)$ or the control $(n=29)$ arm. The study was approved by the respective regional ethical committees (cantons of Vaud, Neuchâtel and Jura). After receiving the approval from all directors of the child care centers, written informed consent was obtained from the parents or legal representatives of 1467 of the 1616 initially selected children (participation rate: 91\%, Figure 1). In each child care center, anthropometric and motor skills were simultaneously assessed on one randomly selected day of the week. As attendance of the children at their child care center was $48 \% \pm 26 \%$ (mean \pm standard deviation; $100 \%$ corresponding to 5 full weekdays from 9 am to $5 \mathrm{pm}$ ), 667 of the participating children were present on the selected examination days. Due to cost and logistic reasons, half of the child care centers of each arm (intervention and control) were randomly selected (total $n=30$ ) to also include physical activity measurements which were performed one week after the other measures. The present analysis includes 529 children (36\% of participating children) who had valid data for body mass index (BMI), age, gender and all 5 motor skills of the obstacle courses. There were no differences between children with and without a valid dataset regarding gender, but the former were slightly older $(3.4 \pm 0.6$ and $3.2 \pm 0.7, \mathrm{p}<0.001)$.

\section{Anthropometry}

Standing height was determined and body weight was measured using an electronic scale (Seca, Basel, Switzerland; accuracy $0.05 \mathrm{~g}$ ). BMI was calculated as weight $\mathrm{kg} /$ $\mathrm{m}^{2}$. Children were classified into two BMI-groups "healthy weight" and "overweight" group (including both overweight and obese children) according to the International Obesity Task Force criteria [28].

\section{Motor skills}

Motor skills measures were adapted from the Zurich Neuromotor Assessment (ZNA) test, a standardized and reliable test for 5 - to 8 -year-old children $[29,30]$. This adaptation and an extension of the test for 3- to 5-yearold children has been recently developed [31] (Figure 2). This test was developed for this age group based on the developmental stages (initial, elementary and mature) according to Gallahue and al. [32]. In a pilot study conducted in two additional child care centers, we computed the test-retest reliability over a two weeks time period $(\mathrm{n}=33, \mathrm{r}=0.5, \mathrm{p}<0.05$ for both evaluators) and the inter-rater correlation $(\mathrm{n}=42, \mathrm{r}=0.7, \mathrm{p}<0.05)$ of the total Basic Motor Score (sum of the 5 motor skills, see below) for two of the three evaluators of the present study.

In this test, the 5 motor skills were performed in two playful obstacle courses (the Cat and the Monkey) and each task was rated on a 5-point scale scoring from 0 for worst to 4 for best. Motor skills testing were carried out in a separate room in groups of 4 to 6 children in the presence of 1 educator and 3 evaluators. Each of both obstacle courses was explained and demonstrated to a subgroup of 2 to 3 children and each child was evaluated and scored individually by one evaluator. This test allows assessing motor skills performance of 6 children with two evaluators within 15 minutes.

In the "Cat" course (Figure 2), children stood up from a chair, ran 3 meters to a pole, turned around it, ran 


\section{Participant flow}

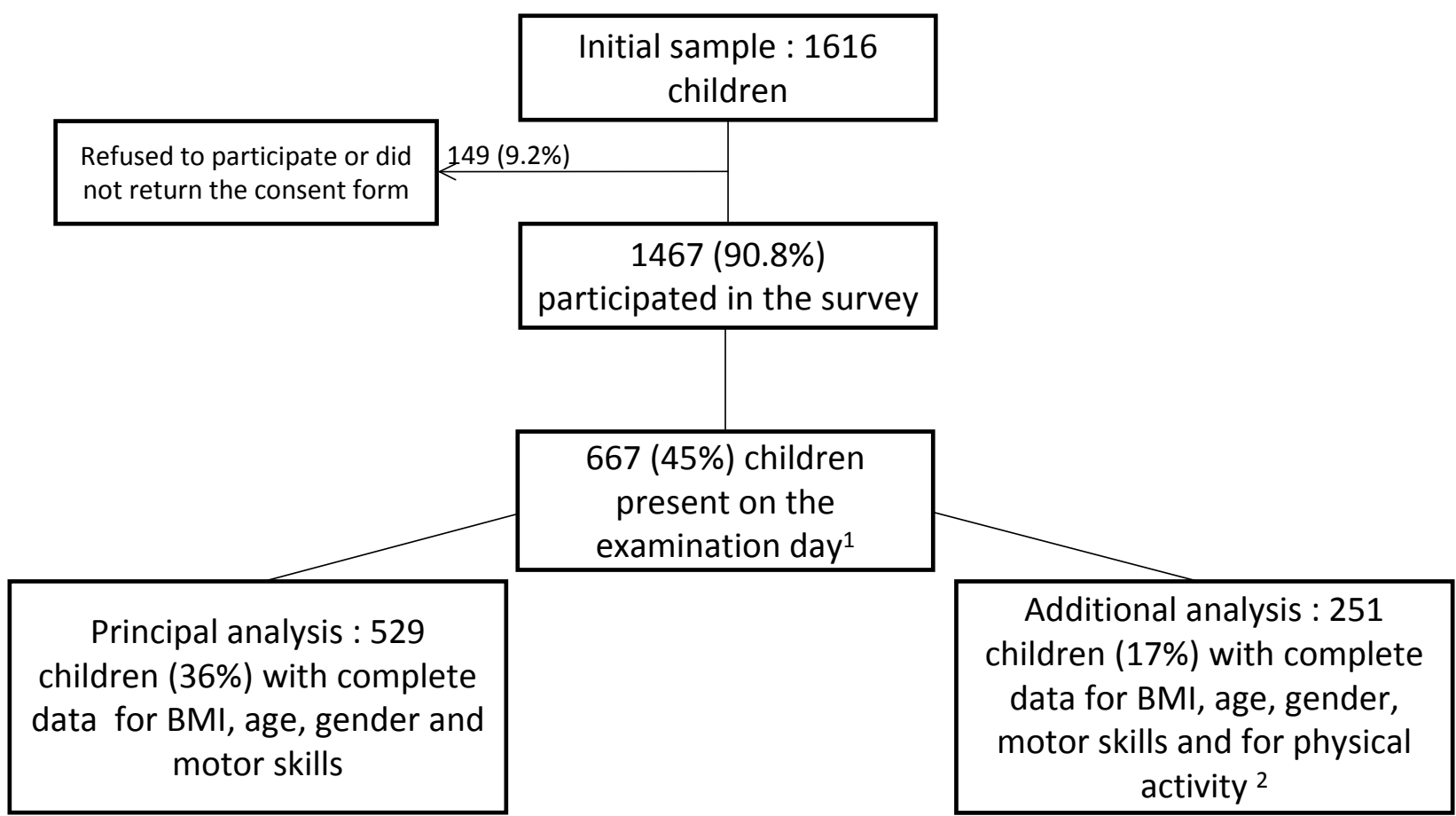

Figure 1 Participant flow. ${ }^{1}$ The numbers of children are due to the low attendance of children at their child care center (mean attendance 48 $\pm 26 \%)$. ${ }^{2}$ Physical activity measures were only performed in 30 out of 58 randomly selected child care centers.

back and climbed up and down a three-step stairs while removing a sticker from the wall on the top of the stairs. The motor skills running (1) and climbing up and down the stairs (2) were scored.

In the "Monkey" course (Figure 2), children balanced on a beam, passed under a tunnel, got up and jumped from a case (height of the first step of the stairs). The motor skills balancing (3), getting up (4) and landing after jumping (5) were scored. To further differentiate children with excellent motor skills, children were additionally asked to jump on one leg as many times as they could. Each motor skill was evaluated using a scale ranging from 0 (unable to perform the task) to 4 (excellent). Refusals ( $\mathrm{n}=60$ out of 589) were removed from the analyses. Two motor scores were calculated to determine an overall motor skills score: 1) an "Integral Motor Score" (sum of 6 motor skills) that included the additional and most difficult task "jumping on one leg". This score ranged from 0 (unable to perform all 6 motor skills) to 24 (best performance on all tasks) and 2) a "Basic Motor Score" (sum of 5 motor skills, regarded as the reference score) that did not include this task and whose score ranged from 0-20. Children, who refused any of the tasks, could not be included in these motor skills score.

\section{Child care-based physical activity}

Physical activity was measured over only one day at the child care center with an accelerometer (GT1M, Actigraph, Florida, USA). The accelerometer was worn around the hip and programmed to save data in $15 \mathrm{~s}$ intervals (epoch size of $15 \mathrm{~s}$ ), as proposed for this age $[25,33]$. The CSA/Actigraph is the most commonly used motion sensor in children and has a good reproducibility, validity and feasibility [34]. This physical activity assessment has been shown to be valid across different activities in 3 to 5 years old children with a Pearson correlation coefficient between $\mathrm{VO}_{2}(\mathrm{ml} / \mathrm{kg}$ per min) and Actigraph counts/epoch of $r=0.82$ [25]. Data was considered as valid if collected for at least 3 hours. This allowed the inclusion of children attending the child care center during half days. Mean total wearing time was $6.1 \pm 1.4$ hours. Sequences of at least $10 \mathrm{~min}$ of consecutive zero values were removed and interpreted as accelerometer not worn [35]. Child care-based total physical activity level was expressed in counts per 


\section{Description of the Basic Motor Score}

The « Cat » course

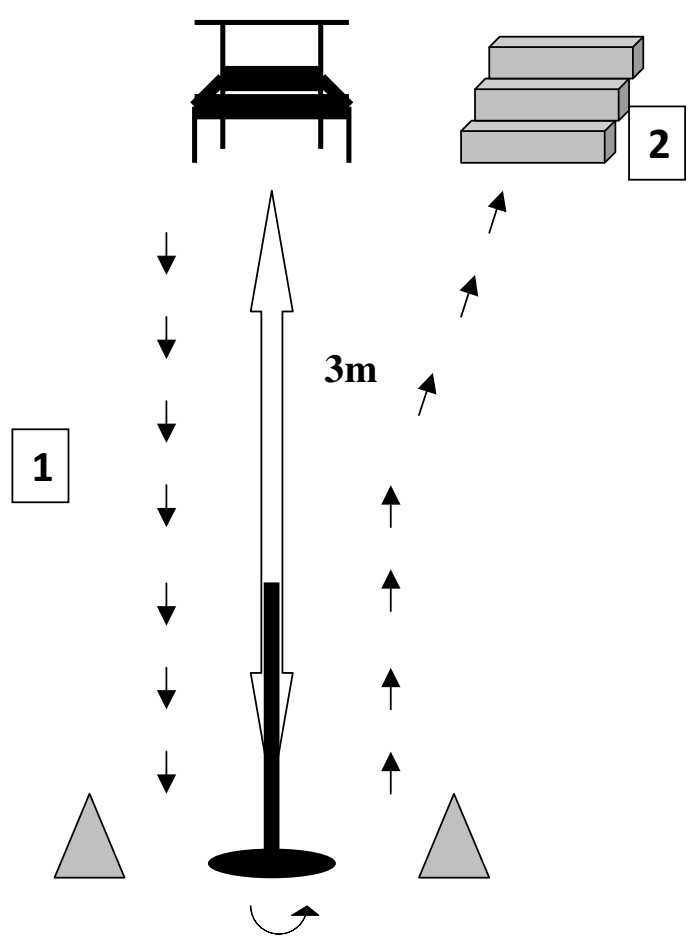

The « Monkey » course

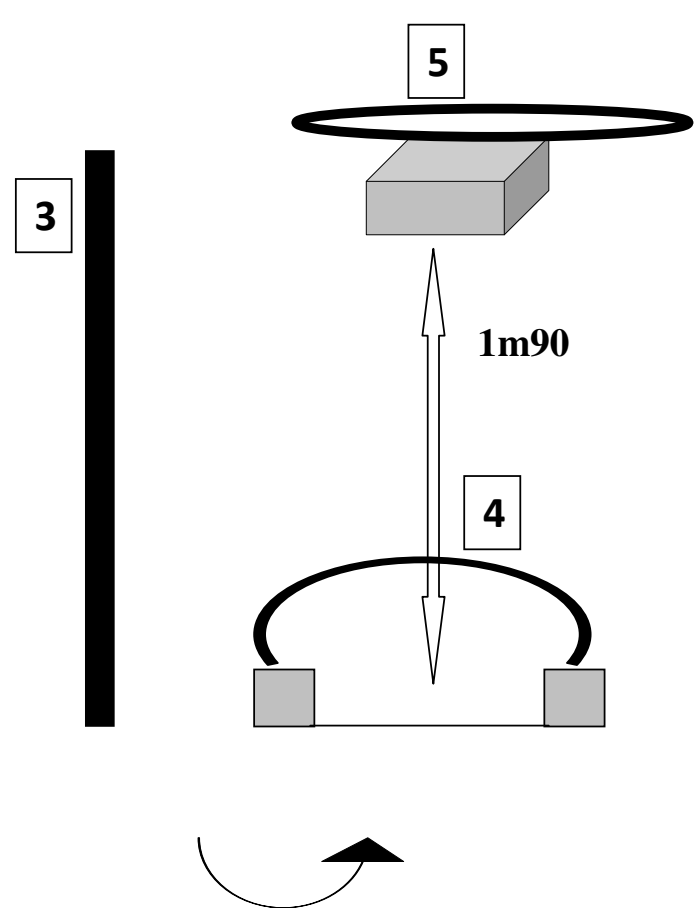

Figure 2 Description of the Basic Motor Score. ${ }^{1}$ Running, ${ }^{2}$ Climbing up and down the stairs, ${ }^{3}$ Balancing, ${ }^{4}$ Getting up, ${ }^{5}$ Landing after jumping.

minute (cpm, total counts recorded divided by total daily wearing time). Physical activity was further categorized into moderate-vigorous physical activity (MVPA), vigorous physical activity (VPA) and sedentary activity. The following age-adjusted cut points were used to define MVPA, VPA and sedentary activity [25]: $\geq 420$ counts/epoch for MVPA; $\geq 842$ counts/epoch for VPA and $<37.5$ counts/epoch for sedentary activity. Data are expressed as the number of epochs/hour above the respective cut-offs. Valid physical activity data were obtained for 275 children, as only half of the child care centers were selected for physical activity measurements. To be able to investigate the same population, physical activity data were only used for those 251 children who also had valid Basic Motor Score measures (Figure 1).

\section{Statistics}

Statistical analyses were performed using STATA version 11.0 (Statacorp, College Station, Tx, USA). Descriptive results were presented as mean \pm standard deviation (SD) for quantitative variables and as percentages for qualitative variables. Differences in age and gender between children with and without a complete dataset were calculated using mixed linear or logistic regression models with child care center (= cluster) as random effect. The differences in anthropometry, motor skills and physical or sedentary activity according to weight status or gender were also calculated using mixed linear or logistic regression models with child care center as random effect. These models were also adjusted for age and, weight status-related differences also for gender. Differences in motor skills were further adjusted for total physical activity (counts/minutes). Between-gender differences in physical activity were also expressed in percentages using girls' physical activities as a denominator. We tested weight status by gender, weight status by age or gender by age interactions. We also tested, if BMI was related to motor skills or activity measures after adjustment for age and gender. Statistical significance was assumed at $p<0.05$. 
Table 1 Children's characteristics

\begin{tabular}{lcccc}
\hline & Total sample & Boys & Girls & P-value \\
\cline { 2 - 5 } $\mathrm{n}(\%)$ & 529 & $268(51 \%)$ & $261(49 \%)$ & \\
Age (years) & $3.4 \pm 0.6$ & $3.4 \pm 0.6$ & $3.4 \pm 0.6$ & 0.9 \\
Weight $(\mathrm{kg})$ & $15.8 \pm 2.2$ & $15.9 \pm 2.0$ & $15.6 \pm 2.3$ & 0.08 \\
Height $(\mathrm{cm})$ & $98.5 \pm 6.2$ & $98.8 \pm 5.7$ & $98.1 \pm 6.7$ & 0.1 \\
Body mass index & $16.2 \pm 1.2$ & $16.3 \pm 1.2$ & $16.2 \pm 1.3$ & 0.3 \\
$\left(\mathrm{~kg} / \mathrm{m}^{2}\right)$ & & & & \\
Overweight & 12.9 & 10.1 & 15.7 & 0.06 \\
children (\%) & & & & \\
\hline
\end{tabular}

Values are means ( \pm standard deviations), unless stated differently.

${ }^{a}$ according to the International Obesity Task Force percentiles

\section{Results}

\section{Characteristics of the participating children}

Table 1 shows the characteristics of the 529 children with a valid dataset (i.e. who had complete data for BMI, age, gender and for all 5 motor skills of the Basic Motor Score). There were no significant gender differences in the anthropometric measures, although overweight prevalence tended to be higher in girls ( $\mathrm{p}=$ 0.053).

No weight status-related differences were found in the single motor skills $(\mathrm{p}>0.1)$. However, a tendency for lower performance in the overweight children was observed in the total Basic Motor Score $(\mathrm{n}=529, \mathrm{p}=$ $0.059)$, but not in the total Integral Motor Score $(\mathrm{n}=$ $411, \mathrm{p}=0.19)$ (Table 2). However, the differences in the total Basic Motor Score did not remain significant after having limited the sample size to only those children who also had a valid Integral Motor Score $(\mathrm{n}=411, \mathrm{p}=$ $0.13)$. No significant differences were found in total physical activity including sedentary activity between healthy weight and overweight children (Table 2 , all $\mathrm{p} \geq$ 0.6). We also tested if BMI was related to motor skills or activity measures: after adjustments for age and gender, increased BMI was related to a decreased score in the running task (beta coefficient of -0.14 and $95 \% \mathrm{CI}$ of -0.28 to $-0.08, \mathrm{p}<0.05)$, but not to the other single motor skills $(\mathrm{p}>0.06)$, both Motor Scores (both $\mathrm{p}>$ 0.25 ) or any of the activity measures (all $\mathrm{p}>0.2$ ).

Boys performed better than girls in running and climbing stairs $(\mathrm{p}=0.039$ and $\mathrm{p}=0.003$, respectively). However, no significant differences were found in the other motor skills, the Basic Motor Score or the Integral Motor Score (Table 3, all p $\geq 0.3$ ). Conversely, boys had significantly higher total physical activity, and spent more time in MVPA and VPA and less time in sedentary activity than girls (Table 3 , all $\mathrm{p} \leq 0.01$ ). This corresponds to a difference in total physical activity of $12 \%$, in MVPA of $22 \%$, in VPA of $25 \%$ and in sedentary activity of $5 \%$. Differences in motor skills running and climbing stairs were no longer significant after adjustment for total physical activity $(\mathrm{p}=0.09$ and $\mathrm{p}=0.21$, respectively).

Restricting all analyses related to motor skills to the children with valid physical activity measures $(n=251)$ did not change the results regarding motor skills, except that overweight children performed less well in the balancing on a beam skill $(\mathrm{p}=0.046)$. Gender differences remained significant in running $(\mathrm{p}=0.004)$, but not in climbing stairs $(\mathrm{p}=0.11)$.

Finally, no significant weight status by gender, weight status by age or gender by age interactions were observed for motor skills and physical activity (all p > 0.08 ).

\section{Discussion}

The goal of our study was to evaluate differences in motor skills and in physical activity according to weight

Table 2 Motor skills, physical activity and sedentary activities according to weight status

\begin{tabular}{|c|c|c|c|}
\hline & \multicolumn{3}{|c|}{ Weight Status } \\
\hline & Healthy Weight & Overweight $^{b}$ & ß-coefficient $(95 \% \mathrm{Cl})$ \\
\hline Motor Scores ${ }^{a}$ & $n=461$ & $n=68$ & \\
\hline \multirow[t]{2}{*}{ Basic Motor Score } & $12.59 \pm 3.43$ & $11.91 \pm 3.55$ & $-0.65(-1.33$ to 0.02$)$ \\
\hline & $n=356$ & $n=55$ & \\
\hline Integral Motor Score & $14.41 \pm 3.82$ & $13.43 \pm 3.81$ & $-0.57(-1.42$ to 0.28$)$ \\
\hline Physical Activity & $n=214$ & $n=37$ & \\
\hline Total physical activity (counts/min) & $610 \pm 211$ & $587 \pm 201$ & $-11.8(-75.4$ to 51.8$)$ \\
\hline Sedentary activity (epochs/hour < 37.5 counts) & $130 \pm 22$ & $132 \pm 24$ & $1.6(-5.4$ to 8.5$)$ \\
\hline MVPA (epochs/hour $\geq 420$ counts) & $29 \pm 13$ & $29 \pm 13$ & $1.1(-3.0$ to 5.1$)$ \\
\hline VPA (epochs/hour $\geq 842$ counts & $8 \pm 6$ & $7 \pm 5$ & $-0.1(-1.8$ to 1.6$)$ \\
\hline
\end{tabular}

Values are means \pm standard deviation and $\beta$-coefficients with $95 \%$ confidence intervals.

Variables were analyzed using a multiple linear regression, adjusted for age, gender and child care center (cluster).

a Basic Motor Score: Reference score for motor skills: sum of the 5 motor skills (running, climbing stairs, balancing on a beam, getting up, landing after jumping); Integral Motor Score: sum of 6 motor skills including the jumping on one leg motor skill

${ }^{\mathrm{b}}$ according to the International Obesity Task Force percentiles Significant gender differences $\left({ }^{*} p<0.05,{ }^{* *} p<0.01,{ }^{* * *} p<0.001\right)$.

MVPA: moderate-and-vigorous physical activity; VPA: vigorous physical activity 
Table 3 Motor skills, physical activity and sedentary activities according to gender

\begin{tabular}{|c|c|c|c|}
\hline \multicolumn{4}{|c|}{ Gender } \\
\hline Motor Scores ${ }^{a}$ & Boys & Girls & B-coefficient $(95 \% \mathrm{Cl})$ \\
\hline \multirow[t]{3}{*}{ Basic Motor Score } & $n=268$ & $n=261$ & \\
\hline & $12.56 \pm 3.62$ & $12.44 \pm 3.27$ & $-0.18(-0.64$ to 0.27$)$ \\
\hline & $n=210$ & $n=201$ & \\
\hline Integral Motor Score & $14.27 \pm 4.06$ & $14.28 \pm 3.58$ & $-0.27(-0.85$ to 0.30$)$ \\
\hline Physical Activity & $n=120$ & $n=131$ & \\
\hline Total physical activity (counts/min) & $641 \pm 220$ & $574 \pm 195$ & $-68.7(-115.0$ to -22.3$) * *$ \\
\hline Sedentary (epochs/hour < 37.5 counts) & $127 \pm 23$ & $134 \pm 20$ & $6.5(1.4$ to 11.5$) * *$ \\
\hline MVPA (epochs/hour $\geq 420$ counts) & $32 \pm 14$ & $26 \pm 11$ & $-6.2(-9.1$ to -3.3$) * * *$ \\
\hline VPA (epochs/hour $\geq 842$ counts) & $9 \pm 6$ & $7 \pm 5$ & $-1.8(-3.0$ to -0.5$) * *$ \\
\hline
\end{tabular}

Values are means \pm standard deviation and $\beta$-coefficients with $95 \%$ confidence intervals. Variables were analyzed using a multiple linear regression, adjusted for age and child care center (cluster).

a Basic Motor Score: Reference score for motor skills: sum of all 5 motor skills (running, climbing stairs, balancing on a beam, getting up, landing after jumping); Integral Motor Score: sum of 6 motor skills including the jumping on one leg skill Significant gender differences $\left({ }^{*} p<0.05,{ }^{* *} p<0.01\right.$, $\left.{ }^{* *} p<0.001\right)$.

MVPA: moderate-and-vigorous physical activity; VPA: vigorous physical activity.

or gender in 2- to 4-year-old children attending child care center. No significant weight status- or genderrelated differences in overall motor skills were found. However, total physical activity and time spent in MVPA and VPA were higher while sedentary activity was lower in the 2- to 4-year-old boys compared to girls.

To our knowledge, weight status-related differences have not been studied in children that young. A few studies in 4- to 6-year-old preschoolers examined differences in motor skills according to weight status [19-21,36], and their results were controversial. One study found no differences [36], while several other studies [19-21] found globally better motor skills (particularly in the more dynamic tests) in healthy weight compared to overweight children. The reasons for the discordance between studies are not clear as many of the tests applied (locomotion, agility and balance) were quite similar. The authors hypothesized that the differences might be due to the fact that performance differences may become apparent at a later age and subsequently increase with age $[21,36]$. We would need more studies to investigate this hypothesis, as it is refuted by a study in school children that did not find any weight-related differences in motor skills [13]. However, our data, generated in a relatively large population of over 500 2-to 4-year-old children, would be in accordance with this assumption: We found a trend for a lower motor performance in overweight children, but no significant weight status-related differences in motor skills. Yet, the few number of overweight children might have reduced our power. Using weight status as a categorical variable is a crude and conservative way to test for the effect of weight on motor performance. However, using BMI instead of weight status did not change the results in a relevant way. The lack of large significant differences in motor skills in this age group highlights the importance of an early prevention to reduce the barriers of later overweight related to physical fitness. Thereby, the child care center may represent an ideal setting.

No weight status-related differences in total physical activity, MVPA, VPA or sedentary activity were found. In school children, differences in physical activity between healthy weight and overweight children are well documented [11,12]. Even in a defined setting during school time, 8- to 10-year-old healthy weight children spent more time in MVPA compared to overweight children [11]. Data in preschool children are more controversial $[22,23]$. In a small study $(n=56)$, Metallinos and al. [22] observed that overweight 3- to 5year-old children spent significantly less time in VPA than their healthy weight counterparts, but total physical activity (counts per minute) did not differ. In another study investigating 3-to 5-year-old children [23], significant weight status-related differences in time spent in MVPA and VPA were found in boys $(\mathrm{n}=118)$, but not in girls $(\mathrm{n}=127)$. Again, total physical activity did not differ. Niederer et al. [21] studied 4- to 6-year-old children $(n=613)$ and found no differences in total and VPA between healthy weight and overweight children, but significant differences in these measures between healthy weight and obese children. Differences between studies could be explained by age or methodological differences such as cut-offs to define overweight/obesity $[28,37,38]$ or the different physical activity intensities $[25,39,40]$. The relatively low PA cut-offs compared to cut-offs [41] used in other studies may also have contributed to the absence of significant differences. Previous reports [21-23] did not compare sedentary activity between healthy weight and overweight preschoolers, although sedentary activity is an important measure in 
regards to overweight and cardiovascular risk [42]. In the current study, no differences were found between healthy weight and overweight children regarding sedentary activity. Overall, our results and the results of previous studies suggest that weight status-related differences in motor skills and in physical activity start to develop around the preschool age and these data underline the importance of early preventive activities.

In the current study, boys performed better than girls in two motor skills (running and climbing stairs), but these differences were no longer significant after summing up the motor skills into the Basic Motor Score. The difference in these two motor skills did also not remain significant after adjusting for differences in physical activity. As we noticed a gender difference in physical activity, these results might imply that girls' motor skills could have improved if they were getting the same amount of physical activity as boys. Interestingly, a study in preschoolers [43] observed that girls in the highest motor skill tertile spent significantly less time in VPA than boys in the highest tertile. Thus, the relationship between PA and motor skills seems to be complex and may also depend on the intensity of physical activity and the level of motor skill performance. Our results regarding motor performance are to some extent in accordance with the literature. Although Cliff and al. [27] observed in a small study ( $\mathrm{n}=46,4.3 \pm 0.7$ years) that girls performed better than boys, Fisher and al. [26] found no gender differences in a study including 394 children (age $4.2 \pm 0.5$ years). Differences in sample size and the choice of motor tasks might explain these contradictory findings. Although the motor test used by Fisher and al. [26] (Movement Assessment Battery) [44] is quite similar to the one used by Cliff and al. [27] (Test of Gross Motor Development) [45], some skills were evaluated in one study but not in the other (balance and skips in the Fisher and al. [26]; run, gallop, leap, slide and ball dribble in the Cliff and al. [27]). Taking the two larger studies together (Fisher et al. and the current one), there seems to be no significant gender differences in global gross motor skills in young children. However, it would be interesting to investigate different gross motor skills domains (i.e. locomotive, manipulative or balancing tasks) in order to explore more precisely potential gender differences, as suggested previously [26].

Contrary to motor skills, we found significant gender differences in total physical activity as well as in the time spent in MVPA, VPA and in sedentary activity. Interestingly, larger differences were observed in the more intense physical activities. Although we only measured over a 8 hour period during one child care day (mean wearing time of 6 hours), our results show that even in a defined setting like child care center, with the same space and a globally similar timetable, boys are more active and less sedentary than girls. This finding is in accordance with previous studies in older children $[22,26]$. Similarly, data in infants, albeit not with accelerometry, confirm our data [24]. Our observed gender differences were not modulated by age and thus were equally present in 2- to 3-year-old children compared to their 4 year-old counterparts. As differences are observed at any age throughout lifespan [22,24,26,46,47], one wonders if gender differences in physical activity are innate or culturally-driven (i.e. impact of "nature versus nurture"). Regardless, child care center educators should be sensitized to these found differences in order to minimize gender inequities in physical activity opportunities in young children.

The present study has a number of limitations. The child care-based investigation of physical activity was performed during one single day (mean wearing time of 6 hours) and only during child care which may not be representative for the whole day, or be representative of a child care day. Considering the literature a minimum of three days would have been more valuable for this assessment [48]. However, Trost and al. suggest that the variability of this assessment observed over a single day seems to decrease as children get younger. Measurement restricted to the child care center setting can also be an advantage allowing detecting differences in a defined setting. But we cannot differentiate whether the social and physical environment in the respective child care center was more attractive to boys than for girls or whether boys may be genetically more active than girls. The motor skills assessment for this specific age has been validated [31]. In our own pilot study, test-retest and inter-rater correlations were 0.5 and 0.7 , respectively. Compared to other motor tests [43-45], reliability and validity of the motor skills tests are only moderate. However, this test has the advantage to assess motor skills performance in a relatively short time, as six children can be assessed within 15 minutes if two raters participate.

Strengths of the study are its large sample size, the investigation of motor skills and of child care-based objectively measured physical activity and the young age of the children.

\section{Conclusions}

In conclusion, our study provides novel information about weight status and gender-related differences in a large sample of 2- to 4-year-old children attending child care center. At this young age, overall motor skills and physical activity do not significantly differ according to weight status. Though there were no gender differences in overall motor skills, boys had higher physical activity level and were less sedentary than girls in this defined 
setting. These results are important to consider when establishing physical activity recommendations or targeting health promotion interventions in young children.

\section{Acknowledgements}

The present study was funded by: Swiss Health Promotion and the Canton of Vaud, Neuchâtel and Jura. We would like to thank the participating children and their parents, as well as all the child care center directors and educators. A special thanks to all students that helped with the assessments.

\section{Author details}

${ }^{1}$ Institute of Sport Sciences, University of Lausanne, Bâtiments administratifs de Vidy, Route de Chavannes 33, 1015 Lausanne, Switzerland. ${ }^{2}$ Child Development Center, University Children's Hospital, 8032 Zürich, Switzerland. ${ }^{3}$ Swiss Tropical and Public Health Institute, University of Basel, Socinstrasse 57, 4002 Basel, Switzerland. ${ }^{4}$ Health League, Rue de la Mouline 8, 1022 Chavannes-près-Renens, Switzerland. ${ }^{5}$ Service of Endocrinology, Diabetes and Metabolism, Centre Hospitalier Universitaire Vaudois, University of Lausanne, Rue du Bugnon 46, 1011 Lausanne, Switzerland.

\section{Authors' contributions}

JJP designed the study and is the principal investigator. JJP, JB and SK established the methods and questionnaires. TK assisted with the motor skills testing and SK with the accelerometry. AB coordinated and conducted the study with the help of JB, AL and JJP. PM gave statistical support. $A B$ wrote the article with the support of JJP. JJP obtained the funding. All authors provided comments on the drafts and have read and approved the final version

\section{Competing interests}

The authors declare that they have no competing interests.

Received: 25 July 2011 Accepted: 9 March 2012

Published: 9 March 2012

\section{References}

1. Kelly T, Yang W, Chen CS, Reynolds K, He J: Global burden of obesity in 2005 and projections to 2030. Int J Obes (Lond) 2008, 32(9):1431-1437.

2. Ogden $\mathrm{CL}$, Carroll MD, Curtin LR, Lamb MM, Flegal KM: Prevalence of high body mass index in US children and adolescents, 2007-2008. JAMA 2010, 303(3):242-249.

3. Tremblay MS, Shields M, Laviolette M, Craig CL, Janssen I, Gorber SC: Fitness of Canadian children and youth: results from the 2007-2009 Canadian Health Measures Survey. Health Rep 2010, 21(1):7-20.

4. Roth K, Ruf K, Obinger M, Mauer S, Ahnert J, Schneider W, Graf C, Hebestreit $\mathrm{H}$ : Is there a secular decline in motor skills in preschool children? Scand J Med Sci Sports 2010, 20(4):670-678.

5. Dollman J, Norton K, Norton L: Evidence for secular trends in children's physical activity behaviour. Br J Sports Med 2005, 39(12):892-897, discussion 897.

6. Barnett LM, Morgan PJ, Van Beurden E, Ball K, Lubans DR: A reverse pathway? Actual and perceived skill proficiency and physical activity. Med Sci Sports Exerc 2011, 43(5):898-904.

7. Barnett LM, van Beurden E, Morgan PJ, Brooks LO, Beard JR: Childhood motor skill proficiency as a predictor of adolescent physical activity. $J$ Adolesc Health 2009, 44(3):252-259.

8. Stodden D, Langendorfer S, Roberton MA: The association between motor skill competence and physical fitness in young adults. Res Q Exerc Sport 2009, 80(2):223-229.

9. Graf C, Koch B, Kretschmann-Kandel E, Falkowski G, Christ H, Coburger S, Lehmacher W, Bjarnason-Wehrens B, Platen P, Tokarski W, et al: Correlation between BMI, leisure habits and motor abilities in childhood (CHILTproject). Int J Obes Relat Metab Disord 2004, 28(1):22-26.

10. Morgan PJ, Okely AD, Cliff DP, Jones RA, Baur LA: Correlates of objectively measured physical activity in obese children. Obesity (Silver Spring) 2008, 16(12):2634-2641.
11. Dorsey KB, Herrin J, Krumholz HM: Patterns of moderate and vigorous physical activity in obese and overweight compared with nonoverweight children. Int J Pediatr Obes 2011, 6(2-2):e547-555.

12. Ekelund U, Sardinha LB, Anderssen SA, Harro M, Franks PW, Brage S, Cooper AR, Andersen LB, Riddoch C, Froberg K: Associations between objectively assessed physical activity and indicators of body fatness in 9- to 10-y-old European children: a population-based study from 4 distinct regions in Europe (the European Youth Heart Study). Am J Clin Nutr 2004, 80(3):584-590.

13. Hume C, Okely A, Bagley S, Telford A, Booth M, Crawford D, Salmon J: Does weight status influence associations between children's fundamental movement skills and physical activity? Res Q Exerc Sport 2008, 79(2):158-165.

14. Cattaneo A, Monasta L, Stamatakis E, Lioret S, Castetbon K, Frenken F, Manios Y, Moschonis G, Savva S, Zaborskis A, et al: Overweight and obesity in infants and pre-school children in the European Union: a review of existing data. Obes Rev 2010, 11(5):389-398.

15. Hesketh KD, Campbell KJ: Interventions to prevent obesity in 0-5 year olds: an updated systematic review of the literature. Obesity (Silver Spring) 2010, 18(Suppl 1):S27-S35.

16. Monasta L, Batty GD, Cattaneo A, Lutje V, Ronfani L, Van Lenthe FJ, Brug J: Early-life determinants of overweight and obesity: a review of systematic reviews. Obes Rev 2010, 11(10):695-708.

17. Monasta L, Batty GD, Macaluso A, Ronfani L, Lutje V, Bavcar A, van Lenthe FJ, Brug J, Cattaneo A: Interventions for the prevention of overweight and obesity in preschool children: a systematic review of randomized controlled trials. Obes Rev 2011, 12(5):e107-e118.

18. Moore LL, Gao D, Bradlee ML, Cupples LA, Sundarajan-Ramamurti A, Proctor MH, Hood MY, Singer MR, Ellison RC: Does early physical activity predict body fat change throughout childhood? Prev Med 2003, 37(1):10-17.

19. Bappert S, Woll A, Bös K: Motorische Leistungsunterschiede bei über- und normalgewichtigen Kindern im Vorschulalter (Differences in motor performance in overweight and normal weight children). Haltung und Bewegung 2003, 23(3):35-37.

20. Mond JM, Stich H, Hay PJ, Kraemer A, Baune BT: Associations between obesity and developmental functioning in pre-school children: a population-based study. Int J Obes (Lond) 2007, 31(7):1068-1073.

21. Niederer I: BMI-Group-Related Differences in Physical Fitness and Physical Activity in Preschoolers: a Cross-Sectional Analysis. Research Quarterly for Exercise and Sport 2011.

22. Metallinos-Katsaras ES, Freedson PS, Fulton JE, Sherry B: The association between an objective measure of physical activity and weight status in preschoolers. Obesity (Silver Spring) 2007, 15(3):686-694.

23. Trost SG, Sirard JR, Dowda M, Pfeiffer KA, Pate RR: Physical activity in overweight and nonoverweight preschool children. Int I Obes Relat Metab Disord 2003, 27(7):834-839.

24. Campbell DW, Eaton WO: Sex Differences in the Activity Level of Infants. Infant Child Dev 1999, 8:1-17.

25. Pate RR, Almeida MJ, Mclver KL, Pfeiffer KA, Dowda M: Validation and calibration of an accelerometer in preschool children. Obesity (Silver Spring) 2006, 14(11):2000-2006.

26. Fisher A, Reilly JJ, Kelly LA, Montgomery C, Williamson A, Paton JY, Grant S: Fundamental movement skills and habitual physical activity in young children. Med Sci Sports Exerc 2005, 37(4):684-688.

27. Cliff DP, Okely AD, Smith LM, McKeen K: Relationships between fundamental movement skills and objectively measured physical activity in preschool children. Pediatr Exerc Sci 2009, 21(4):436-449.

28. Cole TJ, Bellizzi MC, Flegal KM, Dietz WH: Establishing a standard definition for child overweight and obesity worldwide: international survey. BMJ 2000, 320(7244):1240-1243.

29. Largo RH, Caflisch JA, Hug F, Muggli K, Molnar AA, Molinari L: Neuromotor development from 5 to 18 years. Part 2: associated movements. Dev Med Child Neurol 2001, 43(7):444-453.

30. Rousson V, Gasser T, Caflisch J, Largo R: Reliability of the Zurich Neuromotor Assessment. Clin Neuropsychol 2008, 22(1):60-72.

31. Kakebeeke TH, Jenni OG: Neuromotor development from three to five years. Federation of European Neuroscience Societies (Geneva) 2008, 4:211.2, FENS abstract. 
32. In Understanding Motor Development Infants, Children, Adolescents, Adults. Edited by: Gallahue D, Ozmun J. Indianapolis: The McGraw-Hill Companies; 2006:

33. Bailey RC, Olson J, Pepper SL, Porszasz J, Barstow TJ, Cooper DM: The level and tempo of children's physical activities: an observational study. Med Sci Sports Exerc 1995, 27(7):1033-1041.

34. de Vries SI, Bakker I, Hopman-Rock M, Hirasing RA, van Mechelen W: Clinimetric review of motion sensors in children and adolescents. J Clin Epidemiol 2006, 59(7):670-680.

35. Baquet G, Stratton G, Van Praagh E, Berthoin S: Improving physical activity assessment in prepubertal children with high-frequency accelerometry monitoring: a methodological issue. Prev Med 2007, 44(2):143-147.

36. De Toia D, Klein D, Weber S, Wessely N, Koch B, Tokarski W, Dordel S, Struder H, Graf C: Relationship between anthropometry and motor abilities at pre-school age. Obes Facts 2009, 2(4):221-225.

37. Kuczmarski RJ, Ogden CL, Guo SS, Grummer-Strawn LM, Flegal KM, Mei Z, Wei R, Curtin LR, Roche AF, Johnson CL: 2000 CDC Growth Charts for the United States: methods and development. Vital Health Stat 2002, 11(246):1-190.

38. Reilly JJ: Assessment of childhood obesity: national reference data or international approach? Obes Res 2002, 10(8):838-840.

39. Dowda M, Pate RR, Sallis JF, Freedson PS: Accelerometer (CSA) count cut points for physical activity intensity ranges in youth. Med Sci Sports Exerc 1997, 29(5):72.

40. Sirard JS, Trost SG, Dowda M, Pate RR: Calibration of the computer science and applications, Inc. physical activity monitor in preschool children (Abstract). Med Sci Sports Exerc 2001, 33(5):S144.

41. Sirard JR, Trost SG, Pfeiffer KAMD, Pate RR: Calibration and evaluation of an objective measure of physical activity in preschool children. J Phys Act Health 2005, 2005(3):345-357.

42. Cleland V, Venn A: Encouraging physical activity and discouraging sedentary behavior in children and adolescents. J Adolesc Health 2010, 47(3):221-222.

43. Williams HG, Pfeiffer KA, O'Neill JR, Dowda M, Mclver KL, Brown WH, Pate RR: Motor skill performance and physical activity in preschool children. Obesity (Silver Spring) 2008, 16(6):1421-1426.

44. Croce RV, Horvat M, McCarthy E: Reliability and concurrent validity of the movement assessment battery for children. Percept Mot Skills 2001, 93(1):275-280.

45. Ulrich: Test of Gross Motor Development-2 Austin: PRO-ED; 2000.

46. Magnusson KT, Arngrimsson SA, Sveinsson T, Johannsson E: Physical activity of 9 and 15 year old Icelandic children - Public health objectives and relations of physical activity to gender, age, anthropometry and area of living. Laeknabladid 2011, 97(2):75-81.

47. Silva P, Aires L, Santos RM, Vale S, Welk G, Mota J: Lifespan snapshot of physical activity assessed by accelerometry in Porto. J Phys Act Health 2011, 8(3):352-360.

48. Trost SG, Pate RR, Freedson PS, Sallis JF, Taylor WC: Using objective physical activity measures with youth: how many days of monitoring are needed? Med Sci Sports Exerc 2000, 32(2):426-431.

\section{Pre-publication history}

The pre-publication history for this paper can be accessed here: http://www.biomedcentral.com/1471-2431/12/23/prepub

doi:10.1186/1471-2431-12-23

Cite this article as: Bonvin et al:: Weight status and gender-related differences in motor skills and in child care - based physical activity in young children. BMC Pediatrics 2012 12:23.

\section{Submit your next manuscript to BioMed Central and take full advantage of:}

- Convenient online submission

- Thorough peer review

- No space constraints or color figure charges

- Immediate publication on acceptance

- Inclusion in PubMed, CAS, Scopus and Google Scholar

- Research which is freely available for redistribution

Submit your manuscript at www.biomedcentral.com/submit
C Biomed Central 